\title{
Cross-sectional study of changes in physical activity behavior during the COVID-19 pandemic among US adults
}

\author{
Kathleen B. Watson ${ }^{1 *}$, Geoffrey P. Whitfield ${ }^{1}$, George Huntzicker', John D. Omura', Emily Ussery', \\ Tiffany J. Chen ${ }^{1}$ and Robyn Neblett Fanfair ${ }^{2}$
}

\begin{abstract}
Background: Physical activity (PA) provides numerous health benefits relevant to the COVID-19 pandemic. However, concerns exist that PA levels may have decreased during the pandemic thus exacerbating health disparities. This study aims to determine changes in and locations for PA and reasons for decreased PA during the pandemic.

Methods: Reported percentage of changes in and locations for PA and reasons for decreased PA were examined in 3829 US adults who completed the 2020 SummerStyles survey.

Results: Overall, 30\% reported less PA, and 50\% reported no change or no activity during the pandemic; percentages varied across subgroups. Adults who were non-Hispanic Black (Black) or Hispanic (vs. non-Hispanic White, (White)) reported less PA. Fewer Black adults (vs. White) reported doing most PA in their neighborhood. Concern about exposure to the virus (39\%) was the most common reason adults were less active.
\end{abstract}

Conclusions: In June 2020, nearly one-third of US adults reported decreased PA; 20\% reported increased PA. Decreased activity was higher among Black and Hispanic compared to White adults; these two groups have experienced disproportionate COVID-19 impacts. Continued efforts are needed to ensure everyone has access to supports that allow them to participate in PA while still following guidance to prevent COVID-19 transmission.

Keywords: Health disparities, Epidemiology, Environment

\section{Introduction}

The World Health Organization declared the coronavirus disease 2019 (COVID-19) outbreak a pandemic on March 11, 2020 [1]. As of March 15, 2021 severe acute respiratory syndrome coronavirus 2 (SARS-CoV-2), the virus that causes COVID-19, has resulted in more than 15 million cases and 531,766 deaths in the US [2]. Adults of any age with certain underlying health conditions, including cancer, heart conditions such as coronary artery disease,

\footnotetext{
* Correspondence: iyr4@cdc.gov

${ }^{1}$ National Center for Chronic Disease Prevention and Health Promotion, Centers for Disease Control and Prevention, 4770 Buford Highway, NE, Mailstop, S107-5, Atlanta, GA 30341, USA

Full list of author information is available at the end of the article
}

obesity, severe obesity, and type 2 diabetes mellitus (T2DM), are at increased risk of severe illness from COVID-19 [3, 4]. Of particular concern, these conditions are common among US adults, with a prevalence of $42.4 \%$ for obesity [5], 28.8\% for hypertension [6], 9.2\% for T2DM [6], $8.4 \%$ for cancer [6], and $5.6 \%$ for coronary heart disease [6]. Moreover, some racial and ethnic minority groups are more likely to have various chronic conditions and are also being disproportionately affected by COVID-19 [7-13].

Physical activity is an important behavior that provides numerous health benefits $[14,15]$, many of which are particularly relevant during the COVID-19 pandemic [16]. For example, adults who are physically active have

\section{$\triangle B M C$}

C C The Author(s). 2021 Open Access This article is licensed under a Creative Commons Attribution 4.0 International License, which permits use, sharing, adaptation, distribution and reproduction in any medium or format, as long as you give appropriate credit to the original author(s) and the source, provide a link to the Creative Commons licence, and indicate if changes were made. The images or other third party material in this article are included in the article's Creative Commons licence, unless indicated otherwise in a credit line to the material. If material is not included in the article's Creative Commons licence and your intended use is not permitted by statutory regulation or exceeds the permitted use, you will need to obtain permission directly from the copyright holder. To view a copy of this licence, visit http://creativecommons.org/licenses/by/4.0/ The Creative Commons Public Domain Dedication waiver (http://creativecommons.org/publicdomain/zero/1.0/) applies to the data made available in this article, unless otherwise stated in a credit line to the data. 
a lower risk of several chronic conditions that increase the risk of severe illness from COVID-19 including cardiovascular disease, obesity, T2DM, and some cancers $[3,4,14]$. Physical activity can also help manage some of these chronic conditions [14, 15]. Beyond these longterm benefits, physical activity also offers important acute benefits including improved sleep and decreased symptoms of anxiety [14, 15] both of which have been negatively impacted during the COVID-19 pandemic [17-21]. Additionally, emerging evidence suggests that regular physical activity may benefit immune function $[22,23]$ and lessen the severity of acute respiratory infections [24].

Prior to the pandemic about half of US adults met the federal aerobic physical activity guideline (guideline) and disparities existed in physical activity participation $[14,15,25]$. For example, in 2018, there was a 10 percentage point difference in the prevalence of meeting the guideline for non-Hispanic White adults (57.5\%) compared to non-Hispanic Black (45.8\%) and Hispanic (47.8\%) adults [25]. Concerns that physical activity levels might decrease during the pandemic [26] and further exacerbate disparities may stem from a variety of factors. For example, community level prevention strategies such as stay-at-home orders and school and business closures can restrict access to places where people can be active [26]. Several US states and territories began implementing such community prevention strategies in March 2020 [27]. At various times during the pandemic common places for physical activity like parks, trails, and health clubs were closed, in addition to schools and business, in some areas. Additionally, individual-level factors such as concern about exposure to the virus [28, 29] may also influence physical activity behavior.

Because of the quickly evolving nature of the pandemic and public health response measures, it is currently unknown whether physical activity levels in the US have changed during the COVID-19 pandemic. Therefore, the study purpose, which was conducted in June of 2020, was to determine 1) self-reported changes in physical activity behavior among US adults, 2) locations where most of their physical activity was done during the pandemic, and 3) among those doing less, reasons for doing less physical activity, overall and by select characteristics. Findings can help inform efforts to promote physical activity during the COVID-19 pandemic.

\section{Methods}

\section{Survey and analytic sample}

Porter Novelli's 2020 ConsumerStyles database is built from a series of web-based surveys via the Ipsos KnowledgePanel ${ }^{\circ}$ that gathers insights about US consumers. Panel members are randomly recruited using probability- based sampling by address. The panel is continuously replenished and maintains approximately 60,000 panelists. The SpringStyles survey was fielded from 3/19/2020-4/9/ 2020 and was sent to a random sample of 11,097 adult panelists (aged $\geq 18$ years) and a supplemental sample of panelists with children (response rate $=58.2 \%$ ). The SummerStyles survey, fielded from 6/10/2020-6/25/2020, was sent to a random sample of 6463 SpringStyles respondents. A total of 4053 surveys were returned (response rate $=62.7 \%$ ). Those who completed the survey received reward points worth approximately $\$ 5$ and were entered into a monthly sweepstakes. The resulting data were weighted to match the US Current Population Survey proportions for sex, age, household income, race/ethnicity, household size, education, census region, and metro status. Institutional review board approval for this analysis was not needed; the Centers for Disease Control and Prevention was not engaged in human subjects research as personal identifiers were not included in the data file.

Data were excluded $(n=224 ; 5.5 \%)$ if they were missing information on weight status or physical activity behavior (final analytic sample $=3829$ ). Adults with missing data were significantly more likely to be Hispanic and have a high school diploma or less compared to those with complete data.

\section{Measures \\ Physical activity behavior}

To assess changes in physical activity behavior during the COVID-19 pandemic, respondents were asked, "During the COVID-19 pandemic, have you changed the amount of physical activity or exercise that you usually do?" Respondents were able to select one of the following options: "Yes, I did more physical activity/exercise" (more); "Yes, I did less physical activity/exercise" (less); "No, my activity level did not change" (no change); and "I do not do physical activity or exercise". Respondents who selected more, less, or no change were then asked, "Where have you done most of your physical activity or exercise during the COVID-19 pandemic?". Respondents were able to select all that apply from the following options: "Inside my home", "Around my neighborhood", "At a park or public trail", and "Other location". Respondents who indicated they did less activity were asked, "Why have you done less physical activity or exercise during the COVID-19 pandemic?". They were able to select all that apply from the following options: "I worked extra hours", "I was taking care of others (i.e., children)", "I did not have the right equipment", "I did not have enough space", "I couldn't do my preferred activity alone", "I was concerned about virus exposure", and "Other reason".

To assess the status of meeting the federal aerobic physical activity guideline (guideline), modified versions 
of the National Health Interview Survey leisure-time physical activity questions were used [30]. Respondents were asked, during their leisure time, how often in a usual week and, if applicable, the duration they participated in (1) moderate-intensity activities (i.e., sweating or moderate increase in breathing or heart rate) and (2) vigorous-intensity activities (i.e., large increases in breathing or heart rate). Total minutes of moderate-intensityequivalent activity was calculated by counting $1 \mathrm{~min}$ of vigorous-intensity activity as $2 \mathrm{~min}$ of moderate-intensity activity [14]. Respondents were classified as meeting ( $\geq 150 \mathrm{~min} /$ week of moderate-intensity-equivalent physical activity) or not meeting the guideline [14]. Based on the timing of the survey, it is assumed respondents reported usual behavior during the pandemic.

\section{Demographic characteristics}

Respondent characteristics included sex (male, female), age (18-44, 45-64, 65 years and older), race/ethnicity (White, non-Hispanic [White]; Black, non-Hispanic [Black]; Hispanic; non-Hispanic Other including multiracial [Other]), education level (high school diploma or less, some college, college graduate), and region (Midwest, Northeast, South, West) [31]. Weight status was calculated and classified using body mass index (weight $[\mathrm{kg}] /$ height $[\mathrm{m}]^{2}$ ) as: underweight or normal weight $[<25.0 \mathrm{~kg} /$ $\left.\mathrm{m}^{2}\right]$, overweight $\left[25.0-29.9 \mathrm{~kg} / \mathrm{m}^{2}\right]$, obesity $\left[\geq 30 \mathrm{~kg} / \mathrm{m}^{2}\right]$ ) [32]. To assess residence, rural-urban portion [33] data was obtained through the Geocorr 2014: Geographic Correspondence Engine [34] and linked to the respondent's zip code.

\section{Statistical analyses}

Percentages of 1) adults who self-reported more, less, or no change in physical activity during the COVID-19 pandemic, 2) the reported location where most adult's physical activity was done during the COVID-19 pandemic, among adults reporting more, less, or no change in physical activity, and 3) the reasons for doing less during the COVID-19 pandemic, among adults reporting less physical activity, were calculated overall and by respondent characteristics (sex, age, race/ethnicity, weight status, education, aerobic physical activity guideline, region, rural-urban residence). Chi-square tests of independence were used to determine whether each subgroup was associated with change in physical activity. Other race/ethnicity is a heterogeneous group, so their results were not interpreted. Pairwise $t$ tests, with Bonferroni correction, and orthogonal polynomial contrasts were used to identify significant differences and trends by respondent characteristics. Two-sided $P<0.05$ was considered significant. To help reduce survey bias and to be representative of the 2020 US population, the data were weighted based on gender, age, household income, race/ethnicity, household size, education, census region, metro status, and parental status of children 1217 years old. Analyses were conducted in 2020 using SUDAAN version 11.0 (Research Triangle Institute, Research Triangle Park, North Carolina) to account for survey weights.

\section{Results}

During the COVID-19 pandemic, 20.3\% of US adults reported being more active, $30.4 \%$ of adults reported being less active, and $42.7 \%$ of adults reported no change in their amount of physical activity; these percentages varied significantly across subgroups (Table 1). Adults who were female (vs. male), aged 18-44 years (vs. 45 years and older), White (vs. Black), underweight/normal weight or overweight (vs. having obesity), college graduates (vs. some college or less), met (vs. did not meet) the guideline, from the Midwest (vs. South), and lived in urban (vs. rural) areas were more likely to report being more active during the pandemic. In contrast, adults who were Black or Hispanic (vs. White), had at least some college education (vs. less than some college education), and lived in urban (vs. rural) areas were more likely to report being less active during the pandemic.

Among those who reported doing some physical activity, over half reported they did most of their activity inside their home $(61.1 \%)$ and around their neighborhood (51.1\%) while few reported doing most physical activity at a park or public trail $(16.7 \%)$ or at another location (9.6\%) (data not shown). Reported location varied significantly across most subgroups (Figs. 1, 2). For example, Black or Hispanic (vs. White) adults were more likely to report doing most of their physical activity inside the home during the pandemic whereas White (vs. Black) adults were more likely to report doing physical activity around their neighborhood; as age increased, doing physical activity at a park or public trail was less likely.

Among adults who reported less activity during the pandemic, the most common reason reported was concern about exposure to the virus (38.8\%), followed by having an "other" reason (32.2\%), and not having the right equipment (30.7\%) (Table 2). Within reasons for less activity, there were statistically significant differences and trends by sex, age, weight status, education, usual physical activity level, and rural-urban residence. For example, among adults who were less active during the pandemic, younger adults were more likely than older adults to report their reasons being they worked extra hours, took care of others, lacked the right equipment, and had insufficient space. In contrast, older adults were more likely than younger adults to be concerned about exposure to the virus. 
Table 1 Prevalence of reported change in the amount of physical activity done during the COVID-19 pandemic among US adults by demographic characteristics, SummerStyles, $2020^{\circ}$

\begin{tabular}{|c|c|c|c|c|c|c|}
\hline \multirow[t]{4}{*}{ Characteristic } & \multicolumn{2}{|l|}{ Sample Size } & \multicolumn{4}{|c|}{ Change in physical activity (PA) } \\
\hline & \multirow{3}{*}{$\begin{array}{l}\text { Unweighted } \\
\mathrm{N}\end{array}$} & \multirow{3}{*}{$\begin{array}{l}\text { Weighted } \\
\% \text { (SE) }\end{array}$} & \multicolumn{4}{|l|}{ Prevalence } \\
\hline & & & More active & Less active & No change & Do not do PA \\
\hline & & & $\%(\mathrm{SE})$ & $\%(\mathrm{SE})$ & $\%(\mathrm{SE})$ & \\
\hline Total & 3829 & $100(--)$ & $20.3(0.8)$ & $30.4(0.9)$ & $42.7(1.0)$ & $6.6(0.5)$ \\
\hline \multicolumn{7}{|l|}{ Sex } \\
\hline Male & 1942 & $48.6(1.0)$ & $17.0(1.1)^{x}$ & $30.2(1.3)$ & $47.3(1.4)^{x}$ & $5.5(0.7)^{\times}$ \\
\hline Female & 1887 & $51.4(1.0)$ & $23.4(1.2)^{y}$ & $30.6(1.3)$ & $38.3(1.3)^{y}$ & $7.6(0.8)^{y}$ \\
\hline \multicolumn{7}{|l|}{ Age group (years) } \\
\hline $18-44$ & 1267 & $45.1(1.0)$ & $24.9(1.5)^{x}$ & $32.6(1.6)$ & $36.8(1.7)$ & $5.6(0.9)^{x}$ \\
\hline $45-64$ & 1562 & $33.5(0.9)$ & $19.3(1.1)^{y}$ & $29.4(1.3)$ & $44.9(1.4)$ & $6.5(0.8)^{y}$ \\
\hline $65+$ & 1000 & $21.4(0.7)$ & $12.0(1.1)^{\mathrm{z}}$ & $27.3(1.5)$ & $51.8(1.7)$ & $8.9(1.1)^{z}$ \\
\hline \multicolumn{7}{|l|}{ Race/Ethnicity } \\
\hline White, non-Hispanic & 2831 & $64.3(1.0)$ & $21.2(1.0)^{x}$ & $26.5(1.0)^{x}$ & $46.6(1.1)^{x}$ & $5.7(0.5)$ \\
\hline Black, non-Hispanic & 301 & $11.4(0.7)$ & $14.8(2.2)^{y}$ & $38.0(3.2)^{y}$ & $39.4(3.1)^{x}$ & $7.8(1.8)$ \\
\hline Hispanic & 386 & $15.8(0.8)$ & $17.4(2.2)^{x, y}$ & $34.6(2.8)^{y}$ & $38.6(2.9)^{x}$ & $9.5(1.8)$ \\
\hline Other, non-Hispanic ${ }^{b}$ & 311 & $8.5(0.6)$ & $26.0(3.2)^{x}$ & $41.9(3.6)^{y}$ & $25.2(3.0)^{y}$ & $7.0(2.0)$ \\
\hline \multicolumn{7}{|l|}{ Weight status $^{c}$} \\
\hline Underweight / normal & 1261 & $35.6(1.0)$ & $23.3(1.5)^{x}$ & $29.4(1.6)$ & $41.9(1.7)$ & $5.4(0.9)^{x}$ \\
\hline Overweight & 1306 & $32.3(0.9)$ & $21.0(1.4)^{x}$ & $29.9(1.6)$ & $44.6(1.7)$ & $4.6(0.7)^{x}$ \\
\hline Obesity & 1262 & $32.0(0.9)$ & $16.2(1.3)^{y}$ & $32.1(1.6)$ & $41.7(1.6)$ & $10.0(1.1)^{y}$ \\
\hline \multicolumn{7}{|l|}{ Education level } \\
\hline$\leq$ High school diploma & 1187 & $37.8(1.0)$ & $12.7(1.2)^{x}$ & $25.2(1.6)^{x}$ & $50.9(1.8)^{x}$ & $11.2(1.1)^{\mathrm{x}}$ \\
\hline Some college & 1061 & $27.8(0.9)$ & $19.8(1.6)^{y}$ & $31.8(1.9)^{\mathrm{y}}$ & $43.3(1.9)^{y}$ & $5.0(0.8)^{y}$ \\
\hline College graduate & 1581 & $34.4(0.9)$ & $28.9(1.4)^{z}$ & $34.9(1.4)^{y}$ & $33.3(1.3)^{z}$ & $2.9(0.5)^{z}$ \\
\hline \multicolumn{7}{|c|}{ Aerobic physical activity guideline ${ }^{d}$} \\
\hline Does not meet & 1707 & $46.2(0.8)$ & $12.3(1.0)^{x}$ & $31.3(1.4)$ & $44.0(1.5)$ & $12.4(1.0)^{x}$ \\
\hline Meets & 2122 & $53.8(1.0)$ & $27.1(1.2)^{y}$ & $29.6(1.2)$ & $41.6(1.3)$ & $1.6(0.4)^{y}$ \\
\hline \multicolumn{7}{|l|}{ Region } \\
\hline Midwest & 701 & $17.7(0.7)$ & $25.2(2.1)^{x}$ & $32.3(2.2)$ & $37.7(2.2)^{x}$ & $4.8(1.0)$ \\
\hline Northeast & 854 & $20.7(0.8)$ & $18.6(1.6)^{x, y}$ & $31.4(2.0)$ & $43.5(2.1)^{x, y}$ & $6.5(1.1)$ \\
\hline South & 1369 & $38.0(1.0)$ & $17.8(1.3)^{y}$ & $27.6(1.5)$ & $46.9(1.6)^{y}$ & $7.7(0.9)$ \\
\hline West & 905 & $23.5(0.8)$ & $22.0(1.8)^{x, y}$ & $32.5(1.9)$ & $39.1(2.0)^{x}$ & $6.4(1.1)$ \\
\hline \multicolumn{7}{|l|}{ Residence } \\
\hline Rural & 527 & $14.3(0.7)$ & $16.2(2.2)^{x}$ & $20.4(2.1)^{x}$ & $56.9(2.8)^{\mathrm{x}}$ & $6.4(1.5)$ \\
\hline Urban & 3302 & $85.7(0.7)$ & $20.9(0.9)^{y}$ & $32.1(1.0)^{y}$ & $40.4(1.0)^{y}$ & $6.6(0.6)$ \\
\hline
\end{tabular}

${ }^{a}$ Wald Chi-square test of independence between Region and change in physical activity was $P=0.002$; all remaining tests were $P<0.001$

bOther race includes: American Indian, Alaska Native, Asian, Native Hawaiian, other Pacific Islander, and multi-racial

'Underweight / normal, overweight, and obesity classifications are based on the body mass index, which is weight (kg) / height (m) ${ }^{2}$. Underweight / normal: $<$

25.0; overweight: 25.0 -- 29.9; and obesity: $>30.0$

${ }^{\mathrm{d}}$ Participant meets the aerobic component of the physical activity guideline, per self-reported usual week, when they engage in moderate intensity $\geq 150$ min/ week, vigorous intensity $\geq 75 \mathrm{~min} /$ week, or an equivalent combination

$x, y, z$ Across categories of a given characteristic, values in a column that share a letter are not significantly different from each other; values that do not have a superscript are not significantly different

\section{Discussion}

In June 2020, 20\% of US adults reported doing more physical activity during the COVID-19 pandemic while
30\% reported doing less. Reporting less physical activity was more common among adults who were Black and Hispanic, had at least some college education, and lived 


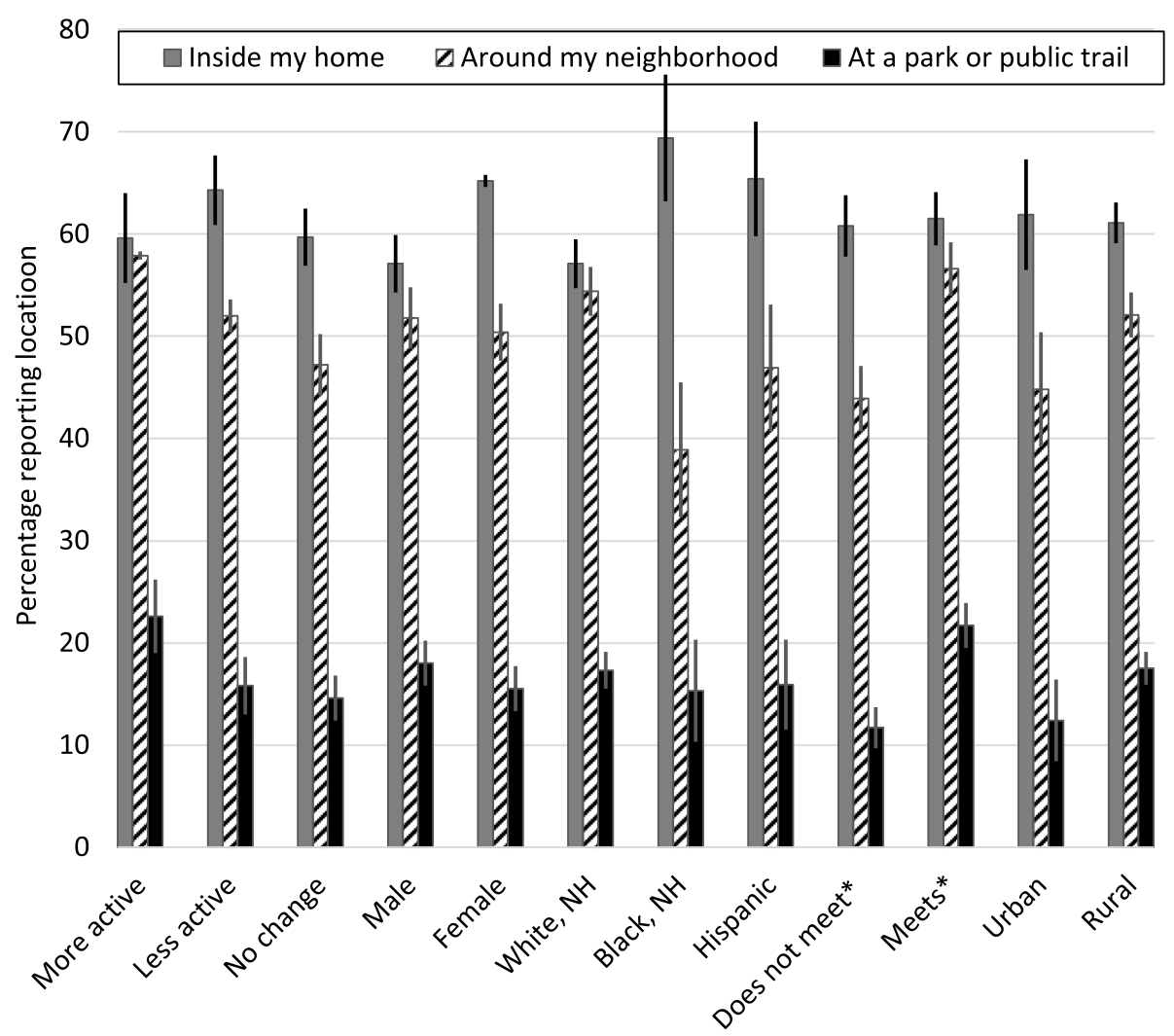

Fig. 1 Prevalence of report locations where most physical activity was done during the COVID-19 pandemic among US adults by change in physical activity, sex, race/ethnicity, meeting guidelines, and rural—urban residence, SummerStyles 2020. ${ }^{*}$ Participant meets the aerobic component of the physical activity guideline, per self-reported usual week, when they engage in moderate intensity $\geq 150$ min/week, vigorous intensity $\geq 75 \mathrm{~min} /$ week, or an equivalent combination, otherwise participant does not meet the aerobic component of the guideline. Significant pairwise differences (all $P<0.001$ unless otherwise noted): inside my home (male vs. female; White, NH vs. Black, NH and Hispanic $(P=0.006)$ ), around my neighborhood (more active vs. no change; White, NH vs. Black, NH; meets vs. does not meet guidelines; urban vs. rural), at a park or public trail (more vs. less and no change, meets vs. does not meet guidelines; urban vs. rural $(P=0.002)$ )

in urban areas compared to their counterparts. Fewer Black (vs. White) adults and adults with obesity (vs. lower weight categories) reported getting most of their physical activity in their neighborhood. The most frequently reported reason for doing less physical activity was concern about exposure to the virus (39\%). Understanding changes in physical activity behavior during the COVID-19 pandemic and underlying reasons for less activity can help identify groups that may benefit from efforts to increase physical activity, thus, maximizing the public health benefits from this important health behavior.

We observed that groups that have been found in prior research to experience severe burdens from COVID-19 morbidity and mortality (i.e., Black and Hispanic populations) [35] were also more likely to report doing less physical activity. Additionally, fewer Blacks than Hispanics or Whites reported being active in their neighborhood. Long-standing systemic health and social inequities have led to communities of predominantly minority racial and ethnic groups and lower- income residents lacking features supporting walking, having limited access to safe, well-maintained parks, and experiencing higher crime rates [36]. Lack of access to supports and opportunities to safely engage in physical activity, combined with disproportionate burdens of COVID-19 and chronic disease during the COVID-19 pandemic, has highlighted the importance of implementing community-based strategies [37] to increase physical activity, particularly for racial and ethnic minority groups.

Our study examines self-reported changes in physical activity during the pandemic by demographic characteristics which few other studies to date have done. Knell et al. surveyed adults between April 15-May 5, 2020 and observed, consistent with our study, more adults reported decreased (39\%) versus increased (25\%) physical activity [38]. Although women were more likely to report an increase than men, no other significant differences in change were reported by age, race/ethnicity, education, or weight status [38]. Potential explanations for the varying findings by subgroup from our study may 


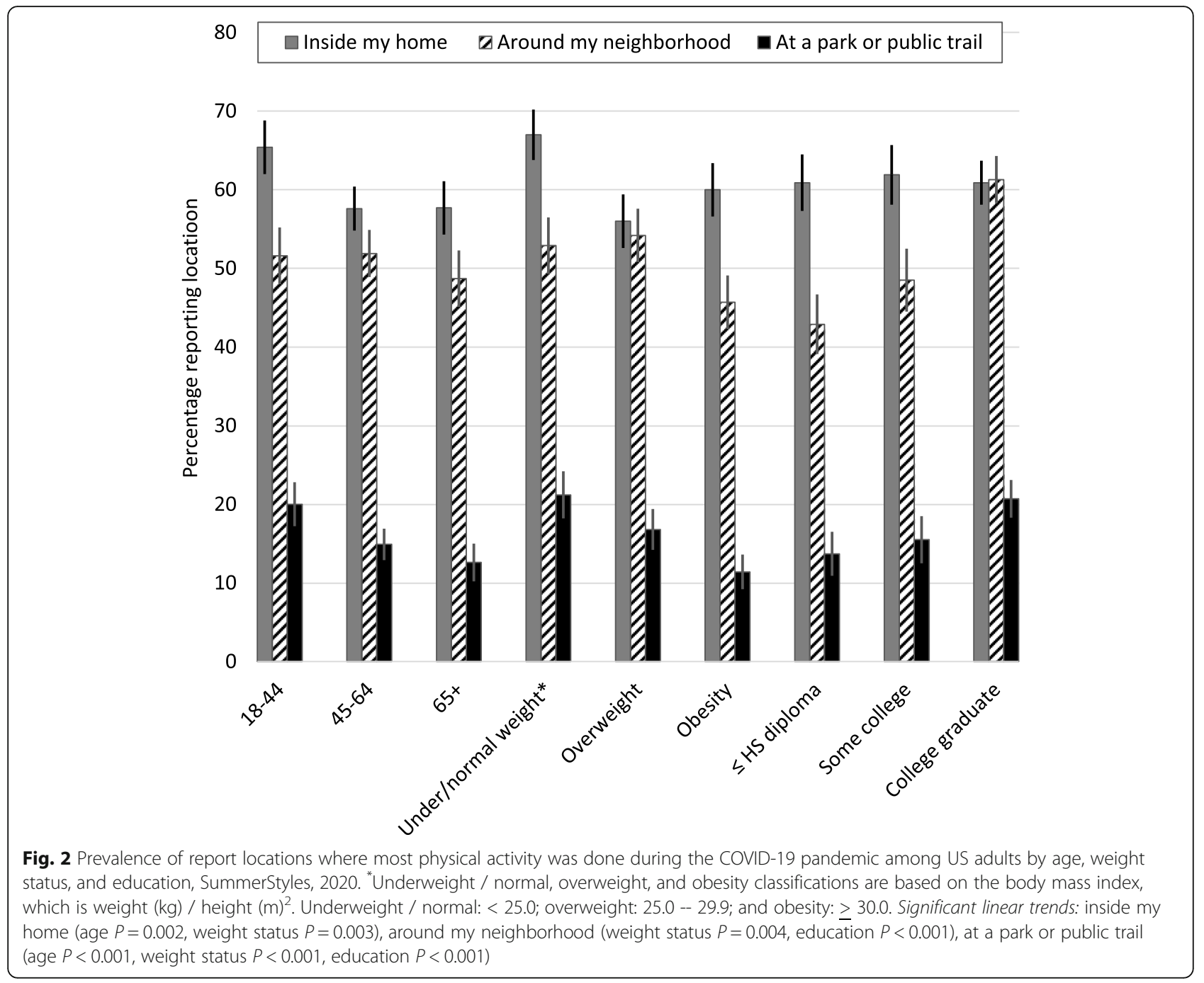

be that Knell et al. [38] surveyed adults primarily from Texas whereas our study was nationwide and weighted to the US population, and our study was conducted slightly later in the pandemic [2].

Beyond the US, studies from other countries have also examined changes in physical activity during the COVID-19 pandemic. Among young German adults, a substantial percentage point difference was observed between those who reported being less (45\%) and more (33\%) active during the pandemic after implementation of a government lockdown [39]. We observed similar patterns but with varying magnitudes, though we were unable to link changes to prevention efforts impacting the respondent at the time of the survey. In Canada, similar proportions of adults reported being more (36\%) and less (35\%) active after COVID-19 restrictions were put in place [40]. When stratified by activity level, $41 \%$ of inactive (defined as not meeting the guideline of 150 min of moderate-intensity equivalent minutes per week) Canadian individuals became less active while 33\% became more active; in contrast, we observed that $31 \%$ of adults not meeting the guideline reported being less active and 12\% reported being more active. Among active Canadian adults, 22\% became less active and $40 \%$ became more active [40], which were similar to our percentages reporting less (30\%) and more (27\%) activity. Among adults participating in insufficient levels of physical activity to meet the guidelines, reasons for differences in being more or less active between studies are unclear. Future work examining factors driving behavior change among insufficiently active adults may assist in the planning and implementation of strategies to help this population obtain sufficient levels of physical activity for substantial health benefits.

Although examining the characteristics of adults who reported being less active during COVID-19 pandemic, examining the characteristics of adults who were more active is also important. Adults who were female, younger (aged 18-44 years), White, not having obesity, a college graduate, lived in urban areas, and from the 
Table 2 Prevalence of reported reasons for doing less physical activity during the COVID-19 pandemic among US adults, SummerStyles, $2020^{a}$

\begin{tabular}{|c|c|c|c|c|c|c|c|c|}
\hline \multirow[t]{3}{*}{ Characteristics } & \multirow{2}{*}{$\begin{array}{l}\text { Sample Size } \\
\text { (unweighted) }\end{array}$} & \multicolumn{7}{|c|}{ Reasons for less physical activity $(n=1136)$} \\
\hline & & $\begin{array}{l}\text { Worked } \\
\text { extra } \\
\text { hours }\end{array}$ & $\begin{array}{l}\text { Taking care } \\
\text { of others } \\
\text { (i.e., children) }\end{array}$ & $\begin{array}{l}\text { Not have } \\
\text { the right } \\
\text { equipment }\end{array}$ & $\begin{array}{l}\text { Not } \\
\text { enough } \\
\text { space }\end{array}$ & $\begin{array}{l}\text { Unable to } \\
\text { do preferred } \\
\text { activity alone }\end{array}$ & $\begin{array}{l}\text { Concerned } \\
\text { about virus } \\
\text { exposure }\end{array}$ & $\begin{array}{l}\text { Other } \\
\text { reason }\end{array}$ \\
\hline & $\mathbf{n}$ & $\%$ (SE) & $\%$ (SE) & $\%$ (SE) & $\%$ (SE) & $\%$ (SE) & $\%$ (SE) & $\%$ (SE) \\
\hline Total & 1136 & $10.0(1.1)$ & $12.5(1.2)$ & $30.7(1.7)$ & $19.2(1.5)$ & $12.7(1.2)$ & $38.8(1.7)$ & $32.2(1.7)$ \\
\hline \multicolumn{9}{|l|}{ Sex } \\
\hline Male & 562 & $9.0(1.3)$ & $8.0(1.3)^{x}$ & $36.1(2.5)^{x}$ & $21.8(2.2)$ & $11.6(1.8)$ & $37.9(2.5)$ & $33.6(2.7)$ \\
\hline Female & 574 & $11.0(1.7)$ & $16.6(1.9)^{y}$ & $25.6(2.3)^{y}$ & $16.7(2.0)$ & $13.7(1.7)$ & $39.6(2.4)$ & $31.0(2.3)$ \\
\hline \multicolumn{9}{|l|}{ Age group (years) } \\
\hline $18-44$ & 403 & $12.9(1.9)^{\mathrm{L}}$ & $16.9(2.1)^{\mathrm{L}}$ & $38.0(3.0)^{\mathrm{L}}$ & $25.1(2.6)^{\mathrm{L}}$ & $14.1(2.1)$ & $33.9(2.8)^{\mathrm{L}}$ & $30.7(3.0)$ \\
\hline $45-64$ & 459 & $11.1(1.6)$ & $10.2(1.7)$ & $26.2(2.3)$ & $15.8(1.9)$ & $11.4(1.8)$ & $41.8(2.6)$ & $32.1(2.4)$ \\
\hline $65+$ & 274 & $0.9(0.6)$ & $5.1(1.6)$ & $19.7(2.5)$ & $9.9(2.1)$ & $11.2(2.2)$ & 45.9 (3.3) & $36.2(3.1)$ \\
\hline \multicolumn{9}{|l|}{ Race/Ethnicity } \\
\hline White, non-Hispanic & 772 & $11.3(1.4)$ & $12.5(1.4)$ & $29.2(2.0)$ & $17.2(1.7)$ & $12.8(1.5)$ & $34.6(2.0)$ & $37.0(2.1)$ \\
\hline Black, non-Hispanic & 107 & $9.4(3.5)$ & $11.8(3.8)$ & $29.7(5.1)$ & $22.7(5.1)$ & $7.2(2.6)$ & $41.6(5.3)$ & $27.0(5.0)$ \\
\hline Hispanic & 131 & $8.6(2.7)$ & $12.3(3.2)$ & $32.5(4.8)$ & $17.0(3.6)$ & $10.7(3.0)$ & $43.4(4.9)$ & $29.8(5.0)$ \\
\hline Other, non-Hispanic ${ }^{b}$ & 126 & $6.8(2.4)$ & $13.6(3.6)$ & $35.8(5.4)$ & $27.5(4.9)$ & $21.5(5.0)$ & $48.4(5.6)$ & $19.5(4.6)$ \\
\hline \multicolumn{9}{|l|}{ Weight status ${ }^{c}$} \\
\hline Underweight/normal & 358 & $9.0(1.8)$ & $14.8(2.3)$ & $35.3(3.2)^{\mathrm{L}}$ & $22.3(2.8)$ & $16.6(2.6)^{\mathrm{L}}$ & $37.7(3.1)$ & $33.7(3.1)$ \\
\hline Overweight & 372 & $8.5(1.6)$ & $10.7(2.0)$ & $31.1(3.1)$ & $17.1(2.5)$ & $10.9(1.9)$ & $37.0(3.0)$ & $34.0(3.3)$ \\
\hline Obesity & 406 & $12.5(2.1)$ & $11.7(1.8)$ & $25.5(2.5)$ & $17.9(2.4)$ & $10.3(1.8)$ & $41.6(2.9)$ & $29.1(2.6)$ \\
\hline \multicolumn{9}{|l|}{ Education level } \\
\hline$\leq$ High school diploma & 283 & $5.4(1.8)^{\mathrm{L}}$ & $10.5(2.2)^{\mathrm{L}}$ & $18.9(2.8)^{\mathrm{L}}$ & $15.6(2.6)$ & $9.8(2.2)$ & $39.6(3.4)$ & $30.8(3.4)$ \\
\hline Some college & 310 & $7.6(1.9)$ & $9.5(2.0)$ & $30.4(3.6)$ & $19.2(3.1)$ & $12.4(2.6)$ & $42.1(3.6)$ & $34.4(3.7)$ \\
\hline College graduate & 543 & $15.4(1.8)$ & $16.3(1.9)$ & $40.1(2.4)$ & $22.0(2.2)$ & $15.1(1.8)$ & $35.6(2.3)$ & $31.8(2.2)$ \\
\hline \multicolumn{9}{|c|}{ Aerobic physical activity guideline $e^{d}$} \\
\hline Did not meet & 530 & $9.0(1.5)$ & $12.5(1.8)$ & $20.4(2.2)^{x}$ & $15.5(1.9)^{x}$ & $13.2(1.9)$ & $42.1(2.6)$ & $35.3(2.6)$ \\
\hline Met guideline & 606 & $10.9(1.6)$ & $12.4(1.6)$ & $40.0(2.5)^{y}$ & $22.5(2.2)^{y}$ & $12.2(1.6)$ & $35.7(2.3)$ & $29.4(2.3)$ \\
\hline \multicolumn{9}{|l|}{ Region } \\
\hline Midwest & 226 & $8.3(2.1)$ & $11.9(2.6)$ & $31.1(4.0)$ & $21.1(3.5)$ & $11.7(2.8)$ & $36.1(3.7)$ & $37.7(4.0)$ \\
\hline Northeast & 254 & $12.1(2.5)$ & $10.9(2.3)$ & $27.5(3.5)$ & 16.9 (3.1) & $11.5(2.2)$ & 34.4 (3.6) & $36.0(3.8)$ \\
\hline South & 360 & $12.3(2.2)$ & $13.4(2.2)$ & $28.0(2.7)$ & $17.3(2.6)$ & $11.7(2.2)$ & 39.7 (3.1) & $30.0(3.0)$ \\
\hline West & 296 & $6.3(1.6)$ & $13.0(2.4)$ & 36.6 (3.6) & $22.3(3.0)$ & $15.7(2.7)$ & $43.3(3.5)$ & $28.2(3.3)$ \\
\hline \multicolumn{9}{|l|}{ Residence } \\
\hline Rural & 119 & $11.3(3.1)$ & $12.2(3.7)$ & $16.9(3.8)^{x}$ & $11.4(3.1)^{x}$ & $7.1(2.5)^{x}$ & $43.4(5.5)$ & $42.0(5.8)$ \\
\hline Urban & 1017 & $9.9(1.1)$ & $12.5(1.3)$ & $32.1(1.8)^{y}$ & $20.0(1.6)^{y}$ & $13.2(1.4)^{y}$ & $38.3(1.8)$ & $31.2(1.8)$ \\
\hline
\end{tabular}

${ }^{a}$ Significant pairwise differences and trends (all $P<0.001$ unless otherwise noted): taking care of others (education trend $P=0.05$ ), not the right equipment (male vs. female $P=0.002$; weight status trend $P=0.02$; rural vs. urban $P=0.01$ ), not enough space (meet vs. not meet guideline $P=0.02$; rural vs. urban $P=0.01$ ), unable to do preferred activity alone (weight status trend $P=0.05$; rural vs. urban $P=0.03$ ), concern about virus (age trend $P=0.005$ )

${ }^{b}$ Other race includes: American Indian, Alaska Native, Asian, Native Hawaiian, other Pacific Islander, and multi-racial

'Underweight / normal, overweight, and obesity classifications are based on the body mass index, which is weight (kg) / height (m) ${ }^{2}$. Underweight / normal: < 25.0; overweight: 25.0 -- 29.9; and obesity: $>30.0$

${ }^{\mathrm{d}}$ Participant meets the aerobic component of the physical activity guideline, per self-reported usual week, when they engage in moderate intensity $\geq 150$ min/ week, vigorous intensity $\geq 75 \mathrm{~min} /$ week, or an equivalent combination

$x, y$ Within categories of a given characteristic, values in a column that share a letter are not significantly different from each other

${ }^{\mathrm{L}}$ For ordinal variables, linear trends across the categories were assessed; Superscript (L) indicates a positive or negative linear trend 
Midwest reported being more active during the COVID19 pandemic. Understanding the subgroups which were more active may also help inform population-level strategies that could be transferred to other groups or in times of non-pandemic.

While community prevention strategies were necessary to slow disease transmission and save lives, some research has linked these strategies to reduced physical activity. Some studies related to the COVID-19 pandemic have assessed changes in physical activity following implementation of community prevention strategies using activity tracker data. Across several countries, studies observed that decreases in steps [41-43] or minutes of moderate-to-vigorous intensity activity per week $[44,45]$ were related to lockdown policies, particularly more restrictive policies [41-45]. Although we were unable to link individual data to community prevention strategies [27], our self-reported findings of adults being less active during the pandemic in June 2020, a period when some prevention strategies were in place across the nation [27], are consistent with findings from other studies [41-45]. While such studies are useful in examining the impact of prevention strategies on physical activity, few have included data on individual characteristics to examine impacts on specific subpopulations. Future work linking community prevention strategies, physical activity, and subgroup characteristics may help identify areas where the prevention strategies, such as stay-at-home orders, may possibly impact physical activity and worsen disparities [26].

In terms of locations where adults participated in physical activity during the COVID-19 pandemic, our study, along with others conducted in Canada and the US, observed that most adults report being physically active at home, including the garage, or in their neighborhood; fewer adults report doing so at a park or trail [40, 41]. Moreover, we observed that adults with higher educational attainment are more likely to be active in their neighborhood compared to their counterparts, similar to findings from other studies using income as a measure of socioeconomic status [41]. Although reasons for these differences in location are unknown, a number of reasons related to location may influence physical activity behavior, e.g. presence and/or safety of places, proximity of these places, weather, other obligations keeping persons at home, or personal preference. Understanding why people chose different places can provide information to practitioners and professionals about how to keep people active during the pandemic [46-48]. For example, professionals in some communities have introduced "safe, slow streets" that provide places to recreate safely on city streets [49], while some have worked to address changes in travel demand and the need for social distancing in other ways such as free bike share programs [50].
Few studies have examined reasons individuals have been less active during the pandemic, and ours is unique in examining such reasons by subgroup populations. One study observed that the most common reason was worry or stress about health, finances, and job security, followed by resource concerns, including limited locations to engage in physical activity [38]. The most common reason we observed overall and among most subgroups (highest in adults $\geq 65$ years) was concern about exposure to the virus, which was also the only health concern we assessed. The second most common reason we observed (apart from an "other" reason) was not having the right equipment. Additional studies, including qualitative analyses examining barriers to physical activity during the pandemic, may help identify whether effective strategies to increase physical activity developed prior to the onset of the COVID-19 pandemic $[14,37,51,52]$ might benefit from modification in pandemic settings.

This study is subject to limitations. First, use of an internet panel survey of volunteers may introduce sample selection bias. However, previous research found general equivalence between random-digit dialing and panel approaches [53, 54]. Second, survey data are selfreported and the validity and reliability of survey questions about physical activity during the pandemic are unknown. Third, we were unable to account for prevention strategies or indicators of community transmission severity (e.g., COVID-19 infection rates, hospitalizations, deaths) where respondents lived which may have influenced physical activity behaviors. Fourth, we were unable to ascertain disability status which may limit or affect their physical activity. Despite these limitations, strengths include the timeliness of data and use of a diverse, nationwide sample allowing stratification by various characteristics. Fifth, our study was limited in what we were not able to measure. We were unable to separately assess changes in key domains of physical activity, especially leisure and transportation, or to assess the main location for physical activity prior to the pandemic. The lists for physical activity locations and reasons for less physical activity were not comprehensive. However, the study still provides information that it useful to practitioners and professionals. Finally, we may have an incomplete picture of physical activity across the nation because some parts of the country had not experienced outbreaks by June 2020. It is possible, even likely, that physical activity habits were much different during the peak periods of late summer 2020 and winter 2021.

\section{Conclusion}

Regular physical activity provides numerous health benefits, many of which are particularly relevant during the COVID-19 pandemic. Even though there were some 
increases in physical activity, our findings suggest physical activity levels have decreased among almost onethird of US adults. Decreased activity was higher among Black and Hispanic (vs. White) adults who are also known to be at risk for severe illness due to COVID-19 and have higher rates of chronic diseases. Continued efforts are needed to ensure everyone has access to supports that allow them to participate in physical activity while still following guidance to prevent COVID-19 transmission. Some population subgroups disproportionately impacted by COVID-19 may benefit from more focused efforts to help mitigate barriers to being physically active during the pandemic.

\section{Acknowledgements}

Not applicable.

\section{Authors' contributions}

KBW, GPW, JTO, TJC, EU, and RNF designed the study conceptualized the paper. KBW performed the analyses. All authors provided input in the interpretation of the data. KBW drafted the manuscript with help from JTO, GPW, and TJC. All authors critically assessed draft of the manuscript. All authors read and approved the final manuscript.

\section{Funding}

The authors received no funding to conduct this study. The findings and conclusions in this manuscript are those of the authors and do not necessarily represent the official position of the Centers for Disease Control and Prevention.

\section{Availability of data and materials}

This study analyses data owned by Porter Novelli Public Services Inc., a third party, so we are unable to archive or share the raw data.

\section{Declarations}

\section{Ethics approval and consent to participate}

Institutional review board approval for this analysis was not needed; the Centers for Disease Control and Prevention was not engaged in human subjects research as personal identifiers were not included in the data file. These data were collected from members of Ipsos's KnowledgePanel. Ipsos maintains a confidentiality agreement with participants to protect their personally identifiable information. Participation is completely voluntary and respondents can leave the panel or refuse to answer any questions on any survey at any time.

\section{Consent for publication}

Not applicable.

\section{Competing interests}

The authors declare that they have no competing interests.

\section{Author details}

1 National Center for Chronic Disease Prevention and Health Promotion, Centers for Disease Control and Prevention, 4770 Buford Highway, NE, Mailstop, S107-5, Atlanta, GA 30341, USA. ${ }^{2}$ National Center for HIV/AIDS, Viral Hepatitis, STD, and TB Prevention, Centers for Disease Control and Prevention, Atlanta, GA, USA.

Received: 12 May 2021 Accepted: 23 June 2021

Published online: 07 July 2021

\section{References}

1. World Health Organization. Coronavirus disease 2019 (COVID-19) situation report-51. Geneva, Switzerland; 2020.
2. Centers for Disease Control and Prevention. CDC COVID Data Tracker [2020]. Available from: https://covid.cdc.gov/covid-data-tracker/\#cases_casesper1 00klast7days.

3. CDC COVID- Response Team. Preliminary estimates of the prevalence of selected underlying health conditions among patients with coronavirus disease 2019 - United States, February 12-march 28, 2020. Morb Mortal Wkly Rep. 2020;69(13):382-6.

4. Centers for Disease Control and Prevention. People with Certain Medical Conditions 2020 [2021]. Available from: https://www.cdc.gov/coronavirus/2 019-ncov/need-extra-precautions/people-with-medical-conditions.html.

5. Hales CM, Carroll MD, Fryar CD, Ogden CL. Prevalence of obesity and severe obesity among adults: United States, 2017-2018. NCHS Data Brief. 2020;360:1-8.

6. Omura JD, Hyde ET, Imperatore G, Loustalot F, Murphy DJ, Puckett M, et al. Trends in meeting the aerobic physical activity guideline among adults with select chronic health conditions, United States, 1998-2018. J Phys Act Health.

7. Price-Haywood EG, Burton J, Fort D, Seoane L. Hospitalization and mortality among black patients and white patients with Covid-19. N Engl J Med. 2020;382(12):2534-43.

8. Gold JAW, Wong KK, Szablewski CM, Patel PR, Rossow J, da Silva J, et al. Characteristics and clinical outcomes of adult patients hospitalized with COVID-19 - Georgia, March 2020. MMWR Morb Mortal Wkly Rep. 2020; 69(18):545-50.

9. Killerby ME, Link-Gelles R, Haight SC, Schrodt CA, England L, Gomes DJ, et al. Characteristics associated with hospitalization among patients with COVID-19 - metropolitan Atlanta, Georgia, March-April 2020. MMWR Morb Mortal Wkly Rep. 2020;69(25):790-4.

10. Stokes EK, Zambrano LD, Anderson KN, Marder EP, Raz KM, El Burai FS, et al. Coronavirus disease 2019 case surveillance - United States, January 22-May 30, 2020. MMWR Morb Mortal Wkly Rep. 2020;69(24):759-65.

11. Millett GA, Jones AT, Benkeser D, Baral S, Mercer $L$, Beyrer C, et al. Assessing differential impacts of COVID-19 on black communities. Ann Epidemiol. 2020;47:37-44.

12. Crook ED, Peters M. Health disparities in chronic diseases: where the money is. Am J Med Sci. 2008;335(4):266-70.

13. Falci L, Shi Z, Greenlee H. Multiple chronic conditions and use of complementary and alternative medicine among US adults: results from the 2012 National Health Interview Survey. Prev Chronic Dis. 2016;13:E61.

14. United States Department of Health and Human Services (HHS). Physical Activity Guidelines for Americans. 2nd ed. Washington, DC: USDHHS; 2018.

15. 2018 Physical Activity Guidelines Advisory Committee. 2018 physical activity guidelines advisory committee scientific report. Washington, DC: U.S. Department of Health and Human Services; 2018.

16. Hacker KA, Briss PA. An ounce of prevention is still worth a pound of cure, especially in the time of COVID-19. Prev Chronic Dis. 2021;18:E03.

17. Bauerle A, Teufel M, Musche V, Weismuller B, Kohler H, Hetkamp M, et al. Increased generalized anxiety, depression and distress during the COVID-19 pandemic: a cross-sectional study in Germany. J Public Health (Oxf). 2020; 42(4):672-8.

18. Galea S, Merchant RM, Lurie N. The mental health consequences of COVID19 and physical distancing: the need for prevention and early intervention. JAMA Intern Med. 2020;180(6):817-8.

19. Vindegaard N, Benros ME. COVID-19 pandemic and mental health consequences: systematic review of the current evidence. Brain Behav Immun. 2020:89:531-42.

20. Wang C, Pan R, Wan X, Tan Y, Xu L, Ho CS, et al. Immediate psychological responses and associated factors during the initial stage of the 2019 coronavirus disease (COVID-19) epidemic among the general population in China. Int J Environ Res Public Health. 2020;17:5.

21. Xiao H, Zhang Y, Kong D, Li S, Yang N. Social capital and sleep quality in individuals who self-isolated for 14 days during the coronavirus disease 2019 (COVID-19) outbreak in January 2020 in China. Med Sci Monit. 2020;26: e923921.

22. Simpson RJ, Campbell JP, Gleeson M, Kruger K, Nieman DC, Pyne DB, et al. Can exercise affect immune function to increase susceptibility to infection? Exerc Immunol Rev. 2020;26:8-22

23. Nieman DC, Wentz LM. The compelling link between physical activity and the body's defense system. J Sport Health Sci. 2019;8(3):201-17.

24. Grande AJ, Keogh J, Silva V, Scott AM. Exercise versus no exercise for the occurrence, severity, and duration of acute respiratory infections. Cochrane Database Syst Rev. 2020;4:CD010596. 
25. Villarroel MA, Blackwell DL, Jen A. Tables of summary health statistics for US adults: 2018 National Health Interview Survey: National Center for Health Statistics 2019, [2019]. Available from: https://ftp.cdc.gov/pub/Health_Sta tistics/NCHS/NHIS/SHS/2018_SHS_Table_A-14.pdf.

26. Sallis JF, Adlakha D, Oyeyemi A, Salvo D. An international physical activity and public health research agenda to inform coronavirus disease-2019 policies and practices. J Sport Health Sci. 2020;9(4):328-34.

27. Moreland A, Herlihy C, Tynan MA, Sunshine G, McCord RF, Hilton C, et al. Timing of state and territorial COVID-19 stay-at-home orders and changes in population movement - United States, march 1-may 31, 2020. MMWR Morb Mortal Wkly Rep. 2020;69(35):1198-203.

28. Ahorsu DK, Lin CY, Imani V, Saffari M, Griffiths MD, Pakpour AH. The fear of COVID-19 scale: development and initial validation. Int J Ment Heal Addict. 2020;1:1-9.

29. Lin CY. Social reaction toward the 2019 novel coronavirus (COVID-19). Soc Health Behav. 2020;3:1-2.

30. Centers for Disease Control and Prevention (CDC). National Center for Health Statistics (NCHS). National Health Interview Survey Questionnaire. Hyattsville: U.S. Department of Health and Human Services, Centers for Disease Control and Prevention; 2021. Available from: ftp://ftp.cdc.gov/pub/ Health_Statistics/NCHS/Survey_Questionnaires/NHIS/2020/EnglishQuest.pdf

31. U.S. Department of Commerce Economics and Statistics Administration, U.S. Census Bureau. Census Regions and Divisions of the United States.

32. National Heart Lung and Blood Institute. Clinical guidelines on the identification, evaluation, and treatment of overweight and obesity in adults: the evidence report. Bethesda: USDHHS, NIH, National Heart, Lung, and Blood Institute; 1998.

33. Ratcliffe M, Burd C, Holder K, Fields A. Defining rural at the U.S. Census Bureau: American Community Survey and Geography Brief. U.S. Department of Commerce Economics and Statistics Administration, U.S. Census Bureau; 2016.

34. Missouri Census Data Center. Geocorr 2014: Geographic correspondence engine: University of Missouri Center for Health Policy; 2016. Updated September 10, 2016. [August 16, 2020]. Available from: https://mcdc. missouri.edu/applications/geocorr2014.html.

35. Centers for Disease Control and Prevention. Health Equity Considerations and Racial and Ethnic Minority Groups 2020 [January 22, 2021]. Available from: https://www.cdc.gov/coronavirus/2019-ncov/community/healthequity/race-ethnicity.html.

36. Taylor W, Lou D. Do all children have places to be active? Disparities in Access to Physical Activity Environments in Racial and Ethnic Minority and Lower-Income Communities. Princeton: A Research Synthesis; 2011.

37. Community Preventive Services Task Force. Physical Activity: Built Environment Approaches Combining Transportation System Interventions with Land Use and Environmental Design. 2016.

38. Knell G, Robertson MC, Dooley EE, Burford K, Mendez KS. Health behavior changes during COVID-19 pandemic and subsequent "Stay-at-Home" orders. Int J Environ Res Public Health. 2020;17:17.

39. Huber BC, Steffen J, Schlichtiger J, Graupe T, Deuster E, Strouvelle VP, et al. Alteration of physical activity during COVID-19 pandemic lockdown in young adults. J Transl Med. 2020;18(1):410.

40. Lesser IA, Nienhuis CP. The impact of COVID-19 on physical activity behavior and well-being of Canadians. Int J Environ Res Public Health. 2020; 17:11.

41. Dunton GF, Wang SD, Do B, Courtney J. Early effects of the COVID-19 pandemic on physical activity locations and behaviors in adults living in the United States. Prev Med Rep. 2020;20:101241.

42. Pepin JL, Bruno RM, Yang RY, Vercamer $V$, Jouhaud P, Escourrou P, et al. Wearable activity trackers for monitoring adherence to home confinement during the COVID-19 pandemic worldwide: data aggregation and analysis. J Med Internet Res. 2020;22(6):e19787.

43. Sun S, Folarin AA, Ranjan Y, Rashid Z, Conde P, Stewart C, et al. Using smartphones and wearable devices to monitor behavioral changes during COVID-19. J Med Internet Res. 2020;22(9):e19992.

44. McCarthy $\mathrm{H}$, Potts $\mathrm{H}$, Fisher A. Physical activity behaviour before, during and after COVID-19 restrictions: a longitudinal smartphone tracking study of 5395 UK adults. J Med Internet Res. 2020;23:e23701.

45. Ong JL, Lau T, Massar SAA, Chong ZT, Ng BKL, Koek D, et al. COVID-19 related mobility reduction: Heterogenous effects on sleep and physical activity rhythms. Sleep. 2020;44:zsaa179.

46. Division of Nutrition, Physical Activity, and Obesity, National Center for Chronic Disease Prevention and Health Promotion. Overcoming Barriers to
Physical Activity [updated December 6, 2020March 5, 2021]. Available from: https://www.cdc.gov/physicalactivity/basics/adding-pa/barriers.html.

47. Whitfield GP, Carlson SA, Ussery EN, Watson KB, Adams MA, James P, et al. Environmental supports for physical activity, National Health Interview Survey-2015. Am J Prev Med. 2018;54(2):294-8.

48. Whitfield GP, Carlson SA, Ussery EN, Watson KB, Brown DR, Berrigan D, et al Racial and ethnic differences in perceived safety barriers to walking, United States National Health Interview Survey - 2015. Prev Med. 2018;114:57-63.

49. City of Los Angeles, Department of Transportation. Slow Streets LA 2020 [February 10, 2021]. Available from: https://ladot.lacity.org/sites/default/files/ documents/slow-streets-faq.pdf.

50. Combs T, Pardo C. Streetplans, Epiandes, MobilityWorks, Datasketch. The "Shifting Streets" Covid-19 mobility dataset; 2020.

51. Fulton JE, Buchner DM, Carlson SA, Borbely D, Rose KM, O'Connor AE, et al. CDC's active people, healthy nation (SM): creating an active America, Together. J Phys Act Health. 2018;15(7):469-73.

52. U.S. Department of Health and Human Services. Step It Up! The Surgeon General's Call to Action to Promote Walking and Walkable Communities. Washington, DC: U.S. Department of Health and Human Services, Office of the Surgeon General; 2015

53. Pollard WE. Use of consumer panel survey data for public health communication planning: an evaluation of survey results. In: Proceedings of the Section on Health Policy Statistics. 2720-2724: American Statistical Association; 2002

54. Fisher $L$, Kane N. Consumer panelist versus random digit dial respondent performance revisited: how similar and how different? Research on research report 64. Chicago, IL: Synovate Inc.; 2004.

\section{Publisher's Note}

Springer Nature remains neutral with regard to jurisdictional claims in published maps and institutional affiliations.
Ready to submit your research? Choose BMC and benefit from:

- fast, convenient online submission

- thorough peer review by experienced researchers in your field

- rapid publication on acceptance

- support for research data, including large and complex data types

- gold Open Access which fosters wider collaboration and increased citations

- maximum visibility for your research: over $100 \mathrm{M}$ website views per year

At BMC, research is always in progress.

Learn more biomedcentral.com/submissions 